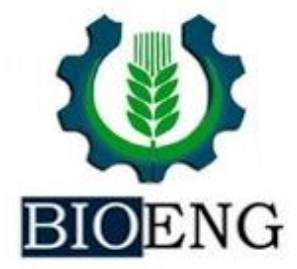

\title{
PROPAGAÇÃO IN VITRO DE JEQUITIBÁ-BRANCO (Cariniana estrellensis): UMA ALTERNATIVA PARA PROGRAMAS DE REFLORESTAMENTO
}

\author{
BIOENG \\ B. É. S. Albino* , R. A. Canatto ${ }^{1}$, A. T. Cordeiro², \\ C. H. Fukushima ${ }^{3}$, A. M. Pilon ${ }^{4}$ \\ ${ }^{1}$ UNESP - Universidade Estadual Paulista, Faculdade de Ciências e Engenharia, Tupã, SP, \\ Brasil \\ ${ }^{2} U F V$ - Universidade Federal de Viçosa (UFV), Viçosa, MG, Brasil \\ ${ }^{3}$ Fitoclone Biotecnologia Vegetal, Viçosa, MG, Brasil \\ ${ }^{4}$ INCAPER - Instituto Capixaba de Pesquisa, Assistência Técnica e Extensão Rural, Laranja \\ da Terra, ES, Brasil.
}

Article history: Received 20 February 2019; Received in revised form 25 April 2019; Accepted 02 May 2019 ; Available online 24 June 2019.

\section{RESUMO}

O objetivo deste trabalho foi determinar um protocolo de micropropagação da espécie jequitibá-branco (Cariniana estrellensis). As sementes foram incubadas em meio Murashige e Skoog (MS). O delineamento utilizado foi o inteiramente casualizado. Os tratamentos de desinfestação consistiram de imersão das sementes em solução de hipoclorito de sódio ( $\mathrm{NaClO})$ por diferentes tempos $(5,10,15$ e 20 minutos). Para a multiplicação in vitro, ápices caulinares, obtidos de vitroplantas, foram inoculados em meio de cultura MS contendo diferentes concentrações $\left(0 ; 0,5 ; 1,0 ; 2,0 \mathrm{mg} \mathrm{L}^{-1}\right)$ de 6-benzilaminopurina (BAP) e cinetina (KIN). No enraizamento in vitro das brotações foram utilizadas diferentes concentrações de ácido indol-3-butírico (AIB) e ácido 1-naftaleno acético (ANA) $\left(0 ; 0,5 ; 1 \mathrm{mg} \mathrm{L}^{-1}\right.$ ). A incubação dos tubos foi realizada no claro em sala de crescimento. Observou-se que a desinfestação utilizando $\mathrm{NaClO}$ por um período de tempo de 5 minutos proporcionou melhor descontaminação e germinação das sementes. A utilização de $1 \mathrm{mg} \mathrm{L}^{-1}$ de BAP adicionada ao meio de cultivo foi eficaz para a formação de brotações na etapa de multiplicação in vitro. A adição de $0,5 \mathrm{mg} \mathrm{L}^{-1}$ da auxina $\mathrm{AIB}$ ao meio de cultivo proporcionou melhor formação de raízes nas brotações, que após 30 dias de aclimatização, tiveram uma taxa média de sobrevivência de $65 \%$. Portanto é necessária a utilização de reguladores de crescimento para a multiplicação in vitro de $C$. estrellensis, sendo possível obter mudas micropropagadas da espécie nas condições do presente trabalho.

Palavras-chave: florestais nativas; germinação; micropropagação.

\section{IN VITRO PROPAGATION OF “JEQUITIBÁ-BRANCO”(Cariniana estrellensis): AN ALTERNATIVE FOR REFORESTATION PROGRAMS}

\begin{abstract}
The objective of the present work was to establish a micropropagation protocol for "jequitibá branco" (Cariniana estrellensis). Seed explants were plated on Murashige and Skoog medium (MS). The design was completely randomized. Disinfection treatments consisted of seed immersion in sodium hypochlorite solution $(\mathrm{NaClO})$ for different time periods $(5,10,15$ and
\end{abstract}

" brunoericufv@gmail.com 
20 minutes). For in vitro multiplication, apical segments obtained from vitro-plants were inoculated into MS culture medium containing different concentrations $(0 ; 0.5 ; 1.0 ; 2.0 \mathrm{mg} \mathrm{L}$ ${ }^{1}$ ) of 6-benzylaminopurine (BAP) and Kinetin (KIN). In vitro rooting of shoots were used different indole-3-butyric acid (IBA) and 1-naftalen acetic acid (NAA) $\left(0 ; 0.5 ; 1 \mathrm{mg} \mathrm{L}^{-1}\right)$ concentrations. Incubation of the tubes was carried out inside the growth room with artificial lighting. It was observed that disinfestation using $\mathrm{NaClO}$ for 5 minutes provided better decontamination and seed germination. One milligram per liter of BAP added to the culture medium was effective for the shoot formation in the in vitro multiplication. The addition of $0.5 \mathrm{mg} \mathrm{L}^{-1}$ of auxin IBA to the culture medium provided better root formation in shoots, which had an average survival rate of $65 \%$ after 30 days of acclimatization. Therefore, it is necessary to use growth regulators for the in vitro multiplication of $C$. estrellensis, making it possible to obtain micropropagated seedlings of the specie in this work conditions.

Keywords: native forest; germination; micropropagation.

\section{INTRODUÇÃO}

A devastação das florestas tropicais constitui um dos mais graves problemas ecológicos enfrentados hoje pelo Brasil (CANATTO et al., 2016). O país possui diversidade de espécies florestais com grande potencial produtivo, no entanto, há carência de informações sobre os aspectos de propagação vegetativa dessas espécies, o que limita a disponibilidade de mudas no mercado, assim como o desenvolvimento de plantios comerciais e de recomposição florestal (HERNANDEZ et al., 2013).

A conservação e o manejo da biodiversidade, mesmo em áreas protegidas nos trópicos, constituem-se em desafios complexos que requerem conhecimentos básicos sobre a distribuição e a abundância de espécies, suas interações mutualistas, sua biologia reprodutiva e a estrutura genética de suas populações (BASSAN et al., 2006). A drástica redução das florestas tropicais elevou as taxas estimadas de extinção de espécies a cifras significativamente altas. Ainda que os números sejam imprecisos e, considerando os processos naturais de extinção, acreditase que o homem tenha elevado estas taxas para algo em torno de 100 a 1000 vezes (MEDEIROS, 2003).

O jequitibá-branco (Cariniana estrellensis), também conhecido por jequitibá-rei, é uma espécie arbórea da família Lecythidaceae, possuindo alto valor econômico (SILVA et al., 2012). O principal produto dessa espécie é a madeira, sendo conhecida nos Estados Unidos como brazilian mahogany mogno-brasileiro (CARVALHO, 2003). A árvore possui qualidades ornamentais, entretanto, devido ao seu grande porte é apenas recomendada para o paisagismo em parques e jardins. A casca e frutos possuem propriedades medicinais sendo utilizada como fortificante, contra a tosse, asma e fraquezas pulmonares (LORENZI, 1992).

Atualmente a propagação de jequitibá-branco no Brasil é feita por sementes, situação que limita a disponibilidade de suas mudas e o desenvolvimento de seus povoamentos. A espécie pode atingir alturas de 30 a 50 metros, com tronco de 70-100 cm de diâmetro (HERNANDEZ et al., 2013). Na literatura são poucos os trabalhos envolvendo cultura de tecidos de $C$. estrelensis. Uma importante contribuição foi dada por DIAS et al., (2012) em trabalho envolvendo a desinfestação e germinação asséptica de sementes.

Alternativamente, um importante método para a multiplicação de plantas lenhosas é a propagação vegetativa. Este método oferece certas vantagens quando comparado à reprodução sexuada, pois aumenta o rendimento e a qualidade genética e fitossanitária das mudas, em qualquer época do ano (ASSIS \& 
TEIXEIRA, 1998). A propagação vegetativa surge como alternativa viável para a produção de mudas de $C$. estrelensis, o que permite a implantação de povoamentos comerciais ou para outros fins (HERNANDEZ et al., 2013).

Entre os vários processos de propagação vegetativa, pode-se destacar a cultura de tecidos in vitro ou clonagem in vitro, também denominada micropropagação. Devido ao tamanho dos propágulos utilizados, a micropropagação é a técnica de cultivo in vitro de maior impacto dentre as diversas técnicas de cultura de tecidos e tem mostrado enorme importância prática e potencial nas áreas agrícola, florestal e hortícola (GRATTAPAGLIA \& MACHADO, 1998; BORGATTO \& HAYASHI, 2002).

Neste contexto, a micropropagação permite produzir um grande número de indivíduos a partir de um explante inicial, requerendo um menor espaço de tempo e utilizando um pequeno espaço físico (KIRST \& SEPEL, 1996). Esta ferramenta biotecnológica pode ser utilizada para propagar espécies florestais ameaçadas (ARAGÃO et al., 2017). Além do mais, torna-se uma tecnologia viável para a regeneração de plantas que apresentam dificuldade na reprodução natural e baixo poder germinativo, apresentando-se como opção ímpar para aquelas espécies nas quais os métodos convencionais de propagação vegetativa não são eficientes (THORPE et al., 1991).

Muitas dificuldades têm sido encontradas na micropropagação de espécies lenhosas, a exemplo da oxidação

\section{MATERIAL E MÉTODOS}

Os experimentos foram realizados na empresa Fitoclone Biotecnologia Vegetal, localizada em Viçosa-MG. O meio de cultura utilizado foi composto pelos sais MS (MURASHIGE \& SKOOG, 1962) meia força, suplementado com vitaminas, $1,5 \%(\mathrm{~m} / \mathrm{v})$ de sacarose e $0,01 \%(\mathrm{~m} / \mathrm{v})$ de mio-inositol. Em seguida, o $\mathrm{pH}$ foi ajustado para 5,8 e acrescido $0,5 \%(\mathrm{~m} / \mathrm{v})$ fenólica que dificulta o estabelecimento in vitro, e é causada pela liberação de compostos fenólicos originados, principalmente, pelo dano causado às células durante a excisão dos explantes (FLORES et al., 1998). Outro entrave encontrado para o uso extensivo da micropropagação é a obtenção de culturas livres de contaminação, principalmente por bactérias e fungos (CHAVES et al., 2005), além do mais, os processos de desinfestação e desinfecção podem causar danos aos tecidos ou mesmo levá-los à morte (ANDRADE et al., 2000). Além disso, a recalcitrância in vitro (falta de resposta morfogenética) deve ser observada, uma vez que entre as espécies lenhosas esta característica é comum (SOUZA \& JUNGHANS, 2006; MOYO et al., 2011).

Apesar das adversidades encontradas na micropropagação de espécies florestais nativas, a exemplo de $C$. estrelensis, as vantagens, do emprego desta técnica, estimulam o desenvolvimento de protocolos mais eficientes. Pelo exposto, aumentam-se as chances de êxito, na micropropagação de C. estrellensis, com a utilização de explantes obtidos da germinação de sementes in vitro.

Este trabalho teve como o objetivo desenvolver um protocolo de estabelecimento, multiplicação, enraizamento e aclimatização para a espécie jequitibá-branco (Cariniana estrellensis), visando à obtenção de mudas para projetos de recomposição ambiental de áreas degradadas.

de agente gelificante ágar, sendo o meio autoclavado a $120^{\circ} \mathrm{C}, 1,1 \mathrm{~Pa}$ por $20 \mathrm{~min}$.

As sementes de $C$. estrellensis foram desinfestadas em álcool etílico 70\% (v/v) por 30 segundos e em seguida em hipoclorito de sódio $(\mathrm{NaClO}) 5 \%(\mathrm{v} / \mathrm{v})$ por 20 minutos. Após esse procedimento, o tegumento das sementes foi removido. Essas foram levadas até a câmara de fluxo, 
e submetidas à desinfestação em álcool etílico $70 \%$ (v/v) durante um minuto e em seguida em $\mathrm{NaClO} 2 \%$ de cloro ativo com 3 gotas de Tween $^{\circledR} 20$ por $5,10,15$ e 20 minutos, mantendo agitação constante. Posteriormente as sementes foram lavadas 3 vezes em água deionizada e autoclavada. A inoculação foi realizada em tubos de ensaio contendo $10 \mathrm{~mL}$ do meio de cultivo semi-sólido. O delineamento experimental foi o inteiramente casualizado totalizando 7 repetições por tratamento, composta por um tubo de ensaio contendo uma semente sem tegumento. As observações quanto à contaminação e germinação foram feitas aos 7, 14 e 21 dias após a inoculação. Esses intervalos de avaliação foram determinados com base em ensaios previamente realizados.

Para a organogênese in vitro, os explantes foram obtidos a partir das vitroplantas geradas da germinação asséptica de sementes. Os ápices caulinares foram inoculados em frascos, contendo aproximadamente $30 \mathrm{~mL}$ de meio MS meia força, suplementado com vitaminas, 2,0\% $(\mathrm{m} / \mathrm{v})$ de sacarose e $0,01 \%(\mathrm{~m} / \mathrm{v})$ de mioinositol. $\mathrm{O}$ experimento foi composto pela utilização de diferentes citocininas, 6benzilaminopurina (BAP) e cinetina (KIN), em diferentes concentrações $(0 ; 0,5 ; 1,0 \mathrm{e}$ 2,0 $\mathrm{mg} \mathrm{L}^{-1}$ ). Em seguida, o $\mathrm{pH}$ foi ajustado para 5,8 e acrescido $0,5 \%(\mathrm{~m} / \mathrm{v})$ de agente gelificante ágar, sendo o meio autoclavado a $120{ }^{\circ} \mathrm{C}, 1,1 \mathrm{~Pa}$ por $20 \mathrm{~min}$. $\mathrm{O}$ delineamento experimental foi $\mathrm{O}$ inteiramente casualizado totalizando 6 repetições por tratamento, compostas por um frasco contendo dois ápices caulinares. As observações, quanto o número de brotos formados e seu tamanho, foram feitas aos 30 dias após a inoculação.

Para o enraizamento in vitro, os explantes foram obtidos a partir das multibrotações geradas da multiplicação dos ápices de $C$. estrellensis. As brotações foram inoculados em frascos, contendo aproximadamente $30 \mathrm{~mL}$ de meio MS, complexo vitamínico, $2 \% \quad(\mathrm{~m} / \mathrm{v})$ de sacarose, $0,01 \%(\mathrm{~m} / \mathrm{v})$ de mio-inositol. O experimento foi composto pela utilização de diferentes auxinas, ácido indol-3butírico (AIB) e ácido 1-naftaleno acético (ANA), em diferentes concentrações (0; 0,5 e $1,0 \mathrm{mg} \mathrm{L}^{-1}$ ). O pH do meio foi ajustado para 5,8 e acrescido $0,5 \%(\mathrm{~m} / \mathrm{v})$ de ágar, antes da autoclavagem a $120^{\circ} \mathrm{C}$, $1,1 \mathrm{~Pa}$ por $20 \mathrm{~min}$. $\mathrm{O}$ delineamento experimental foi o inteiramente casualizado totalizando 10 repetições por tratamento, compostas por um frasco contendo duas brotações. As observações, quanto ao número de raízes formadas, foram feitas aos 30 dias após a inoculação.

Nos experimentos supracitados, a incubação dos frascos foi realizada em sala de crescimento, sob temperatura de $27 \pm 2$ ${ }^{\circ} \mathrm{C}$ com fotoperíodo de $16 / 8 \mathrm{~h}$ (luz/escuro), sob irradiância de $36 \mu \mathrm{mol} \quad \mathrm{m}^{-2} \mathrm{~s}^{-1}$ fornecida por 2 lâmpadas fluorescentes tubulares de 20W (Luz do dia especial, Osram, Brasil).

As vitroplantas enraizadas in vitro foram utilizadas como material vegetal para a aclimatização. Após serem mantidas por 30 dias no meio de cultura, essas foram lavadas e transferidas para copos plásticos de polipropileno $\left(300 \mathrm{~cm}^{3}\right)$ contendo o substrato Plantmax ${ }^{\circledR}$. Após a transferência, os copos foram acondicionados em uma bandeja plástica de polietileno, que foi vedada com filme plástico transparente para a formação de uma câmara úmida. A incubação da bandeja ocorreu por 15 dias no ambiente iluminado da sala de crescimento, assim como citado anteriormente. Após este período, a camada de filme plástico foi removida mantendo-se as mudas por mais 15 dias em sala de crescimento. As mudas que sobreviveram ao processo anteriormente descrito, foram levadas para a casa de vegetação, sob telado com sombrite $50 \%$, para completarem a aclimatização, por um período de 30 dias. 


\section{RESULTADOS E DISCUSSÃO}

Após 7 dias de cultivo, em todos os tratamentos testados, foram observadas sementes de $C$. estrellensis germinadas e com formação de raízes (Fig. 1A). Não foi observada contaminação em nenhum tratamento durante todo o tempo de condução do experimento. A porcentagem de germinação das sementes de $C$. estrellensis foi crescente com o passar do período de incubação. Ao final de 21 dias, em média, $89 \%$ das sementes haviam germinado e formado vitroplantas com sistema radicular inserido no meio de cultivo (Fig. 1B).
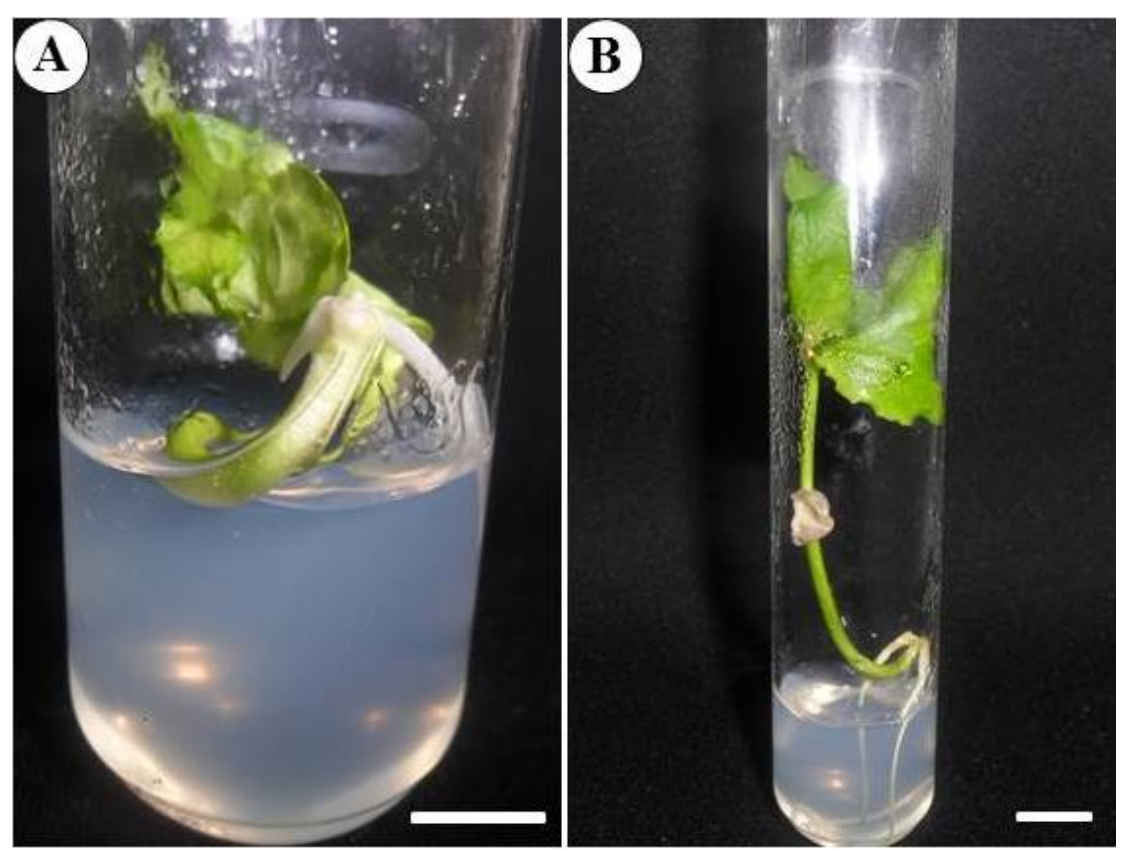

Figura 1: Germinação asséptica de sementes de C. estrellensis submetidas à desinfestação com $\mathrm{NaClO}$ por 5 minutos. A: Semente aos 7 dias de incubação. B: Semente aos 21 dias de incubação. Barras: $1 \mathrm{~cm}$.

Segundo ERIG \& SCHUCH (2003)
as plantas lenhosas apresentam dificuldades para o estabelecimento in vitro, principalmente devido à contaminação por microrganismos. Portanto, os resultados do presente trabalho indicam que, para C. estrellensis, as sementes são uma boa alternativa para o estabelecimento de culturas assépticas que posteriormente podem ser utilizadas em processos de micropropagação. Tais resultados corroboram com os obtidos por SANTOS (2016) e ARAGÃO et al., (2017) trabalhando com micropropagação de $C$. legalis.

$\mathrm{Na}$ literatura, alguns autores sugerem que a utilização de determinadas concentrações de $\mathrm{NaClO}$ podem ser úteis na desinfestação das sementes, mas prejudiciais a sua germinação e desenvolvimento (ZAYAT \& RANAL, 1997; GOLLE, 2007). Portanto, deve-se trabalhar o binômio tempo versus concentração para a obtenção de resultados satisfatórios. Para C. estrellensis, os resultados apontam que o tempo máximo de 5 minutos de exposição ao $\mathrm{NaClO}$ é suficiente para o estabelecimento in vitro de culturas assépticas via germinação de sementes.

Ao final de 30 dias de incubação, em todos os tratamentos contendo BAP ou $\mathrm{KIN}$, os ápices caulinares de $C$. estrellensis formaram brotações e calos friáveis em sua base (Fig. 2A). Para BASSAN et al., (2006) a formação de calos na base do explante é muito comum em espécies lenhosas, sendo considerada desfavorável 
para a micropropagação. Os ápices caulinares inoculados no meio contendo concentrações mais elevadas de BAP chegaram a formar tufos de brotações pequenas (Fig. 2B), diferentemente do observado, em concentrações mais elevadas de KIN, os explantes formaram brotações mais alongadas (Fig. 2C).
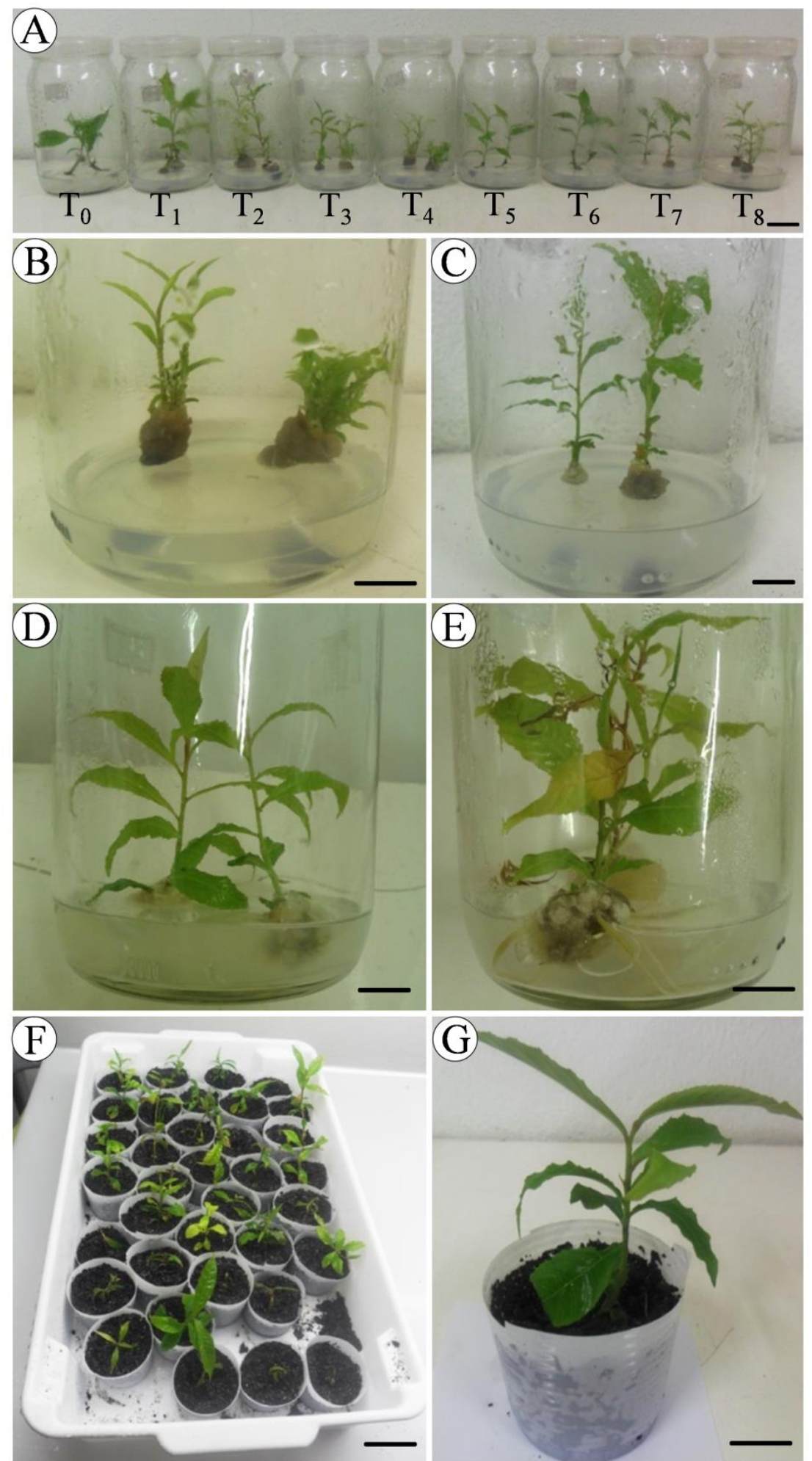

Figura 2: Caracterização do processo de micropropagação a partir de ápices caulinares de $C$. estrellensis. A: Organogênese in vitro em ápices caulinares. $\mathrm{T}_{0}$ : controle; $\mathrm{T}_{1}: 0,5 \mathrm{mg} \mathrm{L}^{-1} \mathrm{BAP}$; $\mathrm{T}_{2}: 1,0 \mathrm{mg} \mathrm{L}^{-1} \mathrm{BAP} ; \mathrm{T}_{3}: 1,5 \mathrm{mg} \mathrm{L}^{-1} \mathrm{BAP} ; \mathrm{T}_{4}: 2,0 \mathrm{mg} \mathrm{L}^{-1} \mathrm{BAP} ; \mathrm{T}_{5}: 0,5 \mathrm{mg} \mathrm{L}^{-1} \mathrm{KIN} ; \mathrm{T}_{6}: 1,0 \mathrm{mg}$ $\mathrm{L}^{-1} \mathrm{KIN} ; \mathrm{T}_{7}: 1,5 \mathrm{mg} \mathrm{L}^{-1} \mathrm{KIN}$; $\mathrm{T}_{8}: 2,0 \mathrm{mg} \mathrm{L}^{-1} \mathrm{KIN}$. Barra: $3 \mathrm{~cm}$. B: Brotações obtidas em meio com 2,0 mg L ${ }^{-1}$ de BAP. Barra $=1 \mathrm{~cm}$. C: Brotações obtidas em meio com $2,0 \mathrm{mg} \mathrm{L}^{-1} \mathrm{de}$ 
KIN. Barra $=1 \mathrm{~cm}$. D: Formação de calos na base dos explantes após 15 dias de incubação em meio contendo 0,5 $\mathrm{mg} \mathrm{L}^{-1}$ de AIB. Barra: $1 \mathrm{~cm}$. E: Emissão de raízes adventícias após 30 dias de incubação em meio contendo $0,5 \mathrm{mg} \mathrm{L}^{-1}$ de AIB. Barra: $1 \mathrm{~cm}$. F: Mudas após 60 dias de aclimatização. Barra: 5 cm. G: Muda aclimatizada. Barra: $2 \mathrm{~cm}$.

Diferenças significativas foram verificadas entre o número de brotos formados por ápice caulinar em função das diferentes concentrações de BAP. As maiores médias foram observadas com a utilização de $1 ; 1,5$ e 2 mg $\mathrm{L}^{-1}$ dessa citocinina. Não ocorreram diferenças significativas no número de brotos com a utilização de KIN adicionada ao meio (Fig. $3)$.

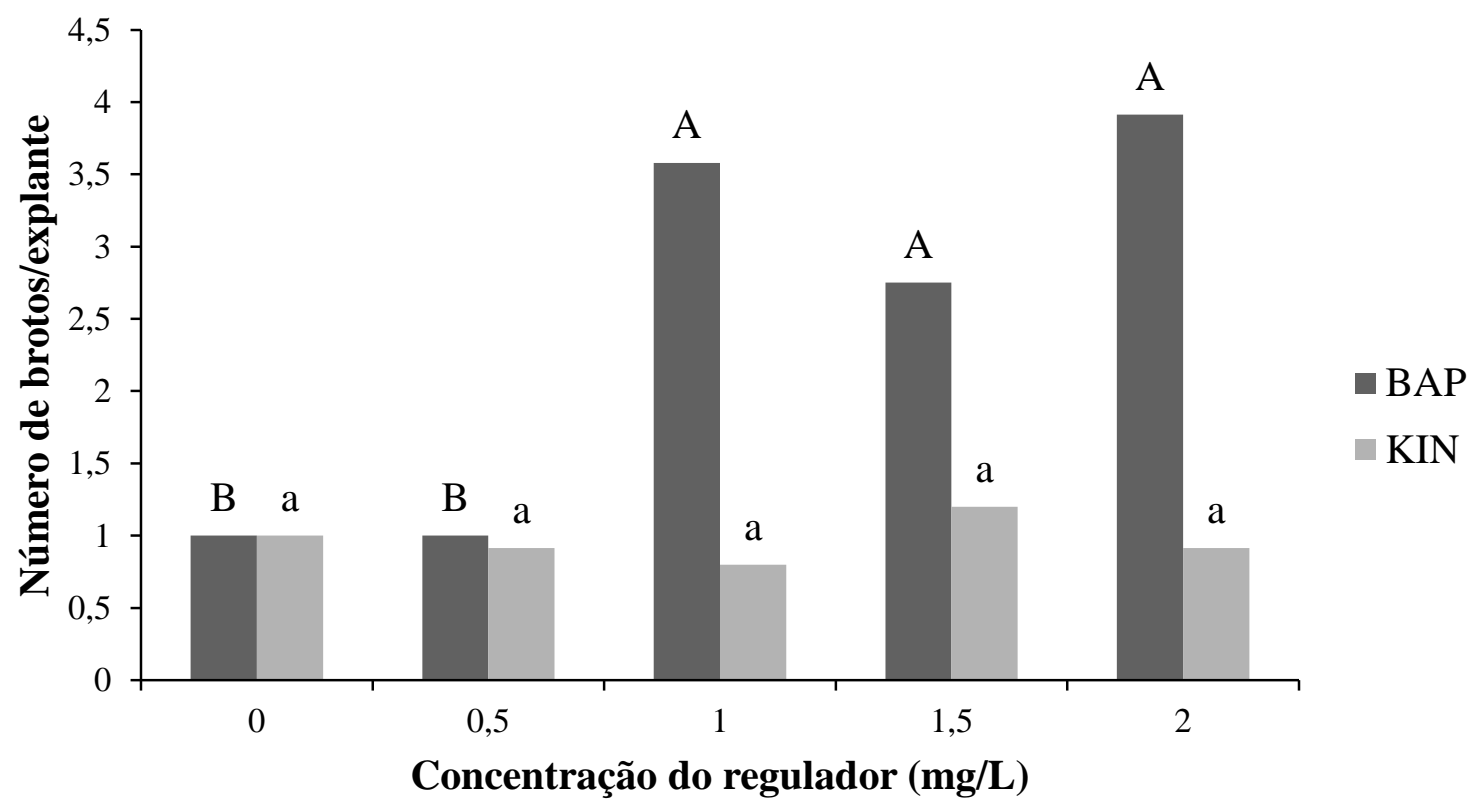

Figura 3: Número de brotos de C. estrellensis gerados a partir de ápices em diferentes concentrações de BAP e KIN. Médias seguidas por letras diferentes apresentam diferenças significativas $(\mathrm{p}<0,05)$ de acordo com o teste Scott-Knott. Letras maiúsculas indicam diferenças significativas entre as concentrações de BAP. Letras minúsculas indicam diferenças significativas entre as concentrações de KIN.

Segundo OLIVEIRA et al. (2013), o BAP é a citocinina mais utilizada nos trabalhos de micropropagação de espécies florestais, podendo ser empregada isoladamente ou em combinação com outras citocininas. GRATTAPAGLIA \& MACHADO (1998) indicaram que a maior eficiência do BAP em relação às citocininas cinetina e $2 \mathrm{iP}$ pode estar na capacidade dos tecidos vegetais metabolizarem os reguladores de crescimento naturais mais rapidamente do que reguladores de crescimento sintéticos. Portanto, a escolha do tipo de citocinina e sua concentração são fatores que influenciam no sucesso da multiplicação in vitro, sendo indispensáveis durante o processo de superação da dominância apical e indução de proliferação a partir de gemas axilares.

O aumento da concentração de BAP adicionado ao meio de cultivo promoveu a diminuição do comprimento das brotações. As menores médias foram observadas com a utilização de 1; 1,5 e $2 \mathrm{mg} \mathrm{L}^{-1}$ de BAP. Diferentemente do observado, com o aumento da concentração de KIN adicionada ao meio de cultivo não houve redução no comprimento das brotações obtidas no experimento (Fig. 4). 


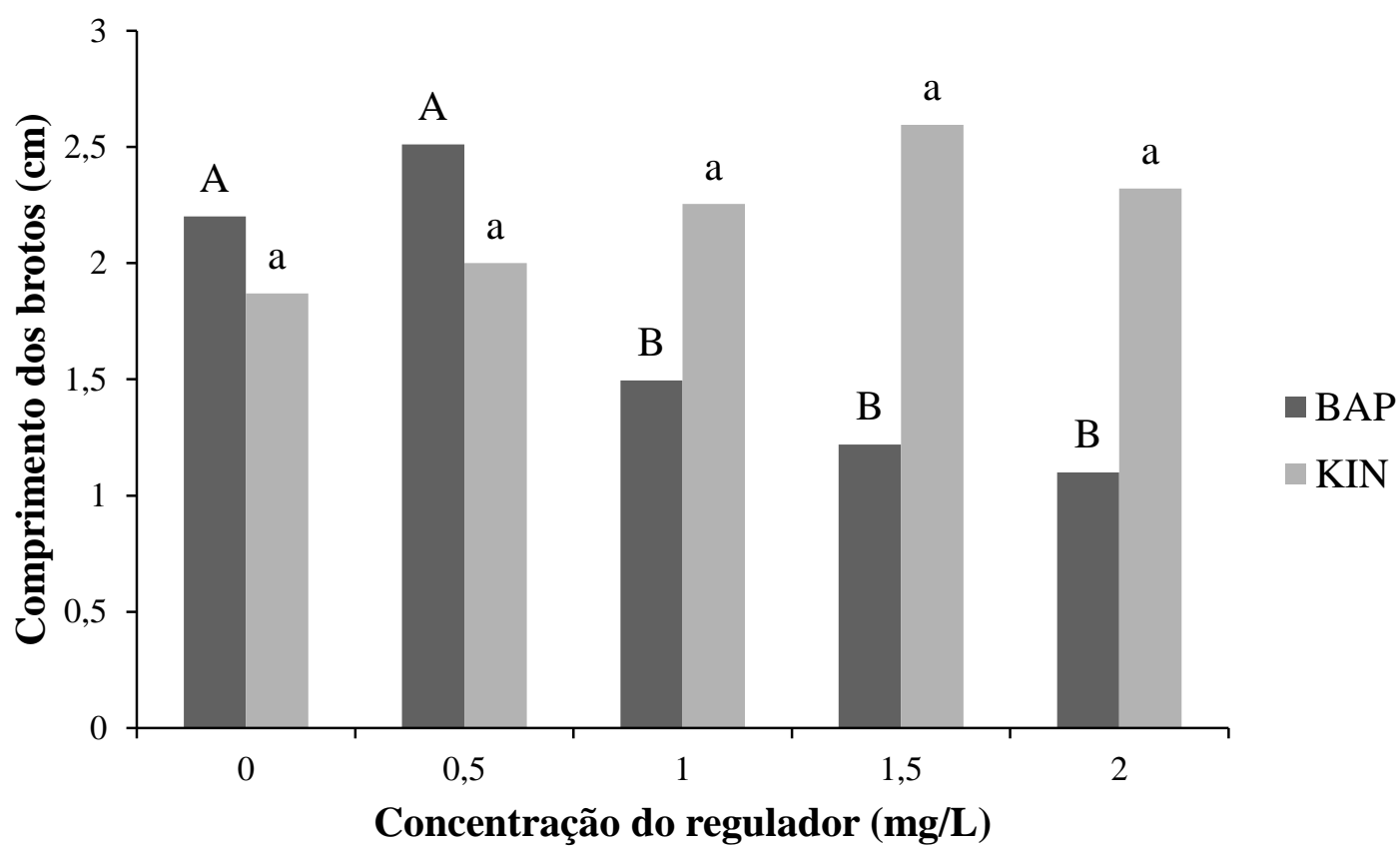

Figura 4: Comprimento dos brotos de C. estrellensis gerados a partir de ápices em diferentes concentrações de BAP e KIN. Médias seguidas por letras diferentes apresentam diferenças significativas $(\mathrm{p}<0,05)$ de acordo com o teste Scott-Knott. Letras maiúsculas indicam diferenças significativas entre as concentrações de BAP. Letras minúsculas indicam diferenças significativas entre as concentrações de KIN.

Resultados semelhantes foram observados por LEITZKE et al., (2010) em trabalho realizado com amoreira-preta (Rubus sp. cultivar Xavante), onde maior comprimento de brotações $(0,8 \mathrm{~cm})$ foi obtido em meio MS na ausência de regulador. Em conformidade com os resultados apresentados, CANATTO et al., (2016), trabalhando com sucupira branca (Pterodon emarginatus Vogel) observaram que o aumento da concentração de BAP adicionada ao meio de cultivo promovia a diminuição do comprimento das brotações, originadas tanto de ápices quanto de segmentos nodais.

As citocininas estimulam o crescimento pela expansão celular mais do que pelo alongamento, induzindo $o$ desenvolvimento de partes aéreas pelo aumento na produção de gemas e folhas (MÁXIMO et al., 2010). Entretanto, de acordo com a literatura (STOYNOVA et al., 2004; TORRES et al., 1998) concentrações mais elevadas que a considerada ótima deste regulador podem atuar inibindo esses efeitos, o que prejudica a multiplicação e o crescimento das espécies.

Decorrido 15 dias de incubação, foi observado intenso calejamento na base dos explantes que foram inoculados no meio de cultivo contendo auxinas (Fig. 2D). Após a formação dos calos, começaram a aparecer às primeiras raízes adventícias nas brotações (Fig. 2E).

Para GRATTAPAGLIA \& MACHADO (1998), a utilização de concentrações excessivas de auxina e sacarose pode favorecer o aparecimento de calos na base dos explantes, dificultando o crescimento e desenvolvimento da parte aérea. A formação de calos tem sido relatada como uma desvantagem para a sobrevivência de plantas no campo, devido à pobre conexão vascular entre o caule e as raízes (AJITKUMAR \& SEENI, 1998; CARVALHO et al., 2005).

Em média $15 \%$ das brotações enraizaram em meio de cultivo sem a adição de auxinas. O AIB se mostrou mais eficiente que ANA para indução do enraizamento in vitro. A melhor taxa de 
enraizamento $(55 \%)$ foi observada com a adição de $0,5 \mathrm{mg} \mathrm{L}^{-1}$ de AIB ao meio de

cultivo (Fig. 5).

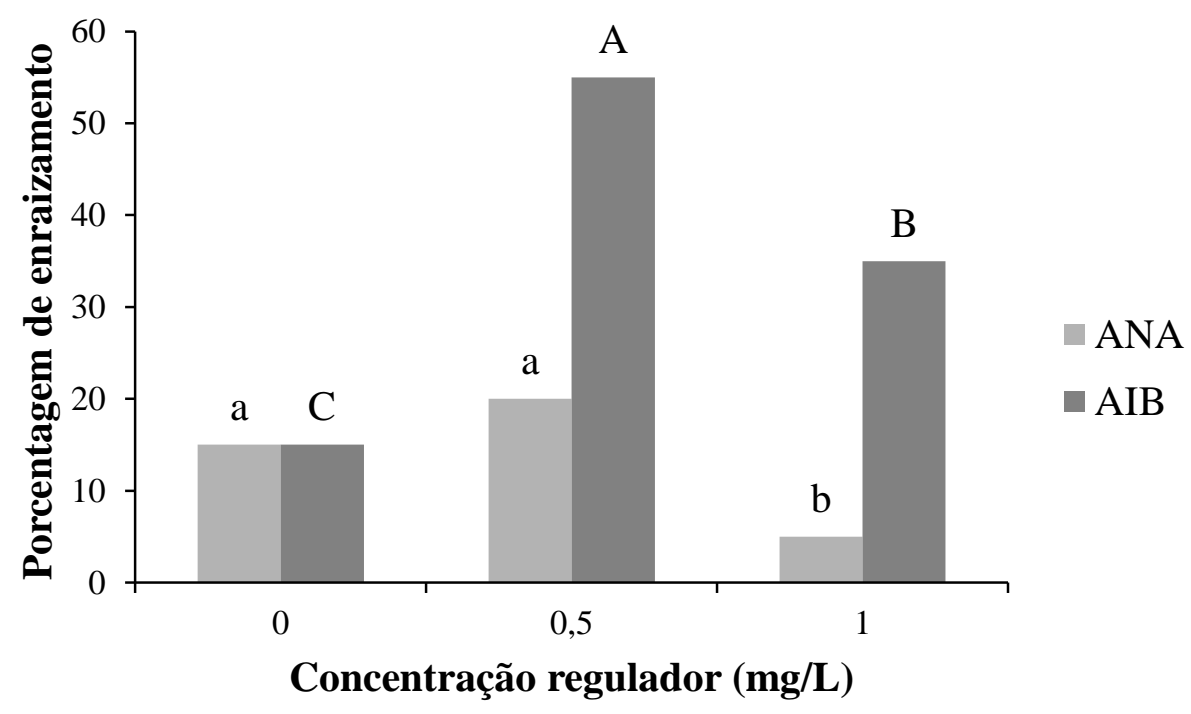

Figura 5: Porcentagem de brotos enraizados de C. estrellensis em meio contendo diferentes concentrações de auxinas. Médias seguidas por letras diferentes apresentam diferenças significativas $(\mathrm{p}<0,05)$ de acordo com o teste Scott-Knott. Letras maiúsculas indicam diferenças significativas entre as concentrações de AIB. Letras minúsculas indicam diferenças significativas entre as concentrações de ANA.

Segundo MELO et al., (2001), o AIB é utilizado com frequência em trabalhos de propagação vegetativa devido a sua maior estabilidade e menor fitotoxidez as plantas lenhosas. No presente trabalho, a maior taxa de enraizamento em $C$. estrellensis foi obtida com a utilização da menor concentração de AIB. Provavelmente a existência de níveis elevados de fitormônios endógenos, pode ter estimulado a rizogênese, como discutido por SOUZA \& PEREIRA (2007) em artigo de revisão. Resultados semelhantes foram obtidos por ARAGÃO et al., (2017), trabalhando com $C$. legalis no enraizamento ex vitro, comprovando a facilidade para a rizogênese em espécies do gênero.

Decorridos 60 dias de aclimatização, a taxa média de sobrevivência das mudas foi de $65 \%$ (Fig. 2F). As brotações menores, com tamanho de até $3 \mathrm{~cm}$, ao serem submetidas ao processo de aclimatização tiveram uma mortalidade muito superior em relação a observada nas mudas maiores que $3 \mathrm{~cm}$ (Fig. 2G).
A aclimatização em condições ex vitro é uma etapa importante na formação de mudas micropropagadas, passando o material vegetal de uma condição heterotrófica para a autotrófica, o que causa estresses fisiológicos (BANDEIRA et al., 2007). Apesar da necessidade de melhorias no processo de aclimatização de C. estrellensis as taxas obtidas são satisfatórias, uma vez que, segundo AUGUSTO (2001), a aclimatização é uma fase crítica para a produção de mudas de plantas lenhosas. As mudas menores que 3 $\mathrm{cm}$ provavelmente estavam mais sensíveis a desidratação e ataque de microorganismos, o que pode ter sido a causa da maior taxa de mortalidade. Adaptações o protocolo de aclimatização serão realizadas visando melhorar as taxas de aclimatização, assim como obtido por ARAGÃO et al., (2017) ao trabalhar com C. legalis.

Em trabalhos futuros esforços serão realizados para a melhoria do processo de micropropagação de C. estrellensis, buscando adequar o protocolo de multiplicação para a utilização de 
biorreatores de imersão temporária. Os resultados obtidos poderão orientar futuras pesquisas com esta espécie em áreas

\section{CONCLUSÕES}

Para a etapa de desinfestação, a utilização de $\mathrm{NaClO}$ por um período de tempo de 5 minutos é a mais adequada para a descontaminação e germinação das sementes de C. estrellensis.

Para a multiplicação in vitro, a utilização de $1 \mathrm{mg} \mathrm{L}^{-1}$ de BAP é adequada para a indução de organogênese em ápices caulinares.

\section{AGRADECIMENTOS}

Os autores agradecem ao $\mathrm{CNPq}$ e a Fitoclone pelo apoio financeiro; e a Universidade Federal de Viçosa pela

\section{REFERÊNCIAS BIBLIOGRÁFICAS}

AJITKUMAR, D.; SEENI, S.; Rapid clonal multiplication through in vitro axillary shoot proliferation of aegle marmelos (L.) corr a medicinal tree. Plant Cell Reports, v. 17: 422-426, 1998.

ANDRADE, M.W.; LUZ, J. M. Q.; LACERDA, A. S.; MELO, P. R. A.; Micropropagação da aroeira (Myracrodruon urundeuva Fr. All). Ciências Agrotécnica, v. 24: 174-180, 2000 .

ARAGÃO, V. P. M.; NAVARRO, B. V.; SILVA, A. T.; SILVEIRA, V.; SANTACATARINA, C.; Micropropagation of Cariniana legalis (Martius) O. Kuntze, an endangered hardwood tree from the Brazilian Atlantic Forest. Plant Cell Culture \& Micropropagation, v. 13 (2): 41-50, 2017.

ASSIS, T. F.; TEIXEIRA, S. L.; Enraizamento de plantas lenhosas. In: TORRES, A. C.; CALDAS, L. S.; BUSO, J. A.; Cultura de tecidos e transformação genética de plantas. multidisciplinares, considerando que ainda existem poucos estudos neste campo.

No enraizamento in vitro a adição de $0,5 \mathrm{mg} \mathrm{L}^{-1}$ de AIB ao meio de cultivo proporciona melhor rizogênese nas brotações.

A aclimatização de vitroplantas de $C$. estrellensis é viável e gera uma taxa média de sobrevivência de $65 \%$.

disponibilização da infraestrutura laboratorial.

Brasília, ABCTP/EMBRAPA - CNPH: 262-297, 1998.

AUGUSTO, C. M. S.; Micropropagação da amoreira-preta cv. Brazos. Dissertação de mestrado. Universidade Federal do Paraná, UFPR, 116p, 2001.

BANDEIRA, F. S.; XAVIER, A.; OTONI, W. C.; LANI, E. R. G.; Aclimatização ex vitro de plantas propagadas pela enxertia in vitro de Eucalyptus urophylla $\mathrm{x}$ E. grandis. Revista Árvore, v. 3, 773-781, 2007.

BASSAN, J. S.; Comportamento in vitro de canafístula [(Peltophorum dubium (Sprengel) Taubert)]. Dissertação Mestrado. Universidade Federal de Pelotas, UFPEL, 88p, 2006.

BASSAN, J. S.; REINIGER, L. R. S.; ROCHA, B. H. G.; SEVERO, C. R. P.; FLÔRES, A. V.; Oxidação fenólica, tipo de explante e meios de cultura no estabelecimento in vitro de Canafístula (Peltophorum dubium (Spreng.) Taub.). 
Ciência Florestal, v. 16(1): 381-390, 2006.

BORGATTO, F.; HAYASHI, T. K.; Biotecnologia de plantas. In: CASTRO, P. R. C.; SENA, J. O. A.; KLUGE.; R. A.; Introdução à fisiologia do desenvolvimento vegetal. Maringá, Eduem: 227-254, 2002.

CANATTO, R. A.; ALBINO, B. E. S.; CORDEIRO, A. T.; Propagação in vitro de sucupira branca (Pterodon emarginatus Vogel): uma espécie florestal nativa. Periódico eletrônico Fórum ambiental da alta Paulista. v. 12(3): 76-88, 2016.

CARVALHO, J. F. R. P.; CARVALHO, C. R.; OTONI, W. C.; Regeneração in vitro de urucum (Bixa orellana L.) a partir de diferentes tipos de explantes. Revista Árvore, v. 29: 887-895, 2005.

CARVALHO, P. R.; Espécies arbóreas brasileiras. Brasília, Embrapa Informação Tecnológica; Colombo, PR: Embrapa. Florestas, 2003.

CHAVES, A. C.; SCHUCH, M. W.; ERIG, A. C.; Estabelecimento e multiplicação in vitro de Physalis peruviana L. Ciência Agrotécnica, v. (29): 1281-1287, 2005.

DIAS, S.; ARAÚJO, T. O.; SARTOR, F. R.; FUKUSHIMA, C. H.; PILON, A. M.; Desinfestação de sementes de Jequitibábranco para propagação in vitro. I Simpósio Internacional de Botânica Aplicada e I Simpósio Nacional de Frutíferas do Norte e Nordeste da UFLA. Lavras, pp. 35, 2012.

ERIG, A. C.; SCHUCH, M. W.; Tipo de explante e controle da contaminação e oxidação no estabelecimento in vitro de plantas de macieira (Malus domestica Borkh.) cvs. Galaxy, Maxigala e Mastergala. Revista Brasileira Agrociência, v. (9): 221-227, 2003.
FLORES, R.; STEFANELLO, S.; FRANCO, E. T. H.; MANTOVANI, N.; Regeneração in vitro de espinheira-santa (Maytenus ilicifolia Mart.). Revista Brasileira de Agrociência, v. 4: 201-205, 1998.

GOLLE, D. P.; Germinação in vitro de Pinus taeda L. a partir de sementes selecionadas. Dissertação de mestrado. Universidade Federal de Santa Maria, UFSM, 97p, 2007.

GRATTAPAGLIA, D; MACHADO, M. A.; Micropropagação. In: TORRES, A. C.; CALDAS, L. S.; BUSO, J. A.; Cultura de tecidos e transformação genética de plantas. Brasília: Embrapa-SPI/EmbrapaCNPH: 183-260, 1998.

KIRST, M.; SEPEL, L. M. N.; Micropropagação de Cedrella fissilis Vellozo a partir de ápices de plantas. Simpósio sobre ecossistema naturais do Mercosul. Santa Maria. pp. 119-126, 1996.

LEITZKE, L. N.; DAMIANI, C. R.; SCHUCH, M. W.; Influência do meio de cultura, tipo e concentração de citocininas na multiplicação in vitro de amoreira-preta e framboeseira. Ciência e Agrotecnologia, v. 34: 352-360, 2010.

LORENZI, H.; Árvores brasileiras. Nova Odessa, Editora Plantarum: 352, 1992.

MÁXIMO, W. P. F.; SANTOS, B. R.; MARTINS, J. P. R.; BARBOSA, S.; BEIJO, L. A.; PAIVA, L. V.; Influência da cinetina na multiplicação in vitro de Handroanthus impetiginosus Mattos. XIX Congresso de pós-graduação da UFLA, Lavras, pp. 56, 2010.

MEDEIROS, J. D.; A biotecnologia e a extinção de espécies. Biotecnologia Ciência e Desenvolvimento, v. 30(1): 109-113, 2003. 
MELO, B.; PINTO, J. E. B. P.; LUZ, J. M. Q.; PEIXOTO, J. R.; JULIATTI, F. C.; Efeitos de ANA e AIB in vitro no enraizamento e crescimento da parte aérea da plântula de Guarirobeira [Syagrus oleracea (Mart) Becc.]. Bioscience Journal, v. 17: 49-59, 2001.

MOYO, M.; FINNIE, J. F.; VAN STADEN, J.; Recalcitrant effects associated with the development of basal callus-like tissue on caulogenesis and rhizogenesis in Sclerocarya birrea. Plant Growth Regulation, v. 63(1): 187-195, 2011.

MURASHIGE, T.; SKOOG, F.; A revised medium for rapid growth and bioassays with tobacco tissue cultures. Physiologia Plantarum, v. 15(1): 473-497, 1962.

OLIVEIRA, L. S.; DIAS, P. C.; BRONDANI, G. E.; Micropropagação de espécies florestais brasileiras. Pesquisa Florestal Brasileira, 33: 445-460, 2013.

SANTOS, P. M. D.; Biometria, conservação de germoplasma e multiplicação in vitro de jequitibás-rosa do sul de minas gerais. Dissertação de mestrado. Universidade Federal de Alfenas, UNIFAL-MG, 79p, 2016.

SILVA, L. F.; SILVA, M. L.; CORDEIRO, S. A.; Análise econômica de plantios de Jequitibá- branco (Cariniana estrellensis). Revista Agrogeoambiental, v. 4: 1-10, 2012.

SOUZA, A. S.; JUNGHANS, T. G.; Introdução à micropropagação de plantas. Cruz das Almas, Embrapa Mandioca e Fruticultura Tropical: 152, 2006.

SOUZA, A. V.; PEREIRA, M. A. S.; Enraizamento de plantas cultivadas in vitro. Revista Brasileira de Plantas Medicinais, v. 9: 103-117, 2007.
STOYNOVA, B. E.; KARANOV, E.; PETROV. P.; HALL, M. A.; Cell division and cell expansion in cotyledons of Arabidopsis seedlings. New Physiologist, v. 162: 471-480, 2004.

THORPE, T. A.; HARRA, Y. I. S.; KUMAR, P. P.; Application and micropropagation to forestry. In: DEBERGH, P. C.; ZIMMERMAN, R. H.; Micropropagation: technology and application, Dordrecht Kluwer Academic Pu: 311-336, 1991.

TORRES, A. C.; CALDAS, L. S.; BUSO, J. Á.; Cultura de Tecidos e Transformação Genética de Plantas. Brasília, Embrapa: 509, 1998.

HERNANDEZ, W.; XAVIER, A.; PAIVA, H. N.; WENDLING, I.; Propagação vegetativa do jequitibá-rosa (Cariniana estrellensis (Raddi) kuntze) por estaquia. Revista Árvore, v. 37(5): 955-967, 2013.

ZAYAT, A. G.; RANAL, M. A.; Germinação de sementes de capiçova. Pesquisa Agropecuária Brasileira, v. 32: 71-80, 1997. 